\title{
LMF Regimen
}

National Cancer Institute

\section{Source}

National Cancer Institute. LMFRegimen. NCI Thesaurus. Code C9602.

A chemotherapy regimen consisting of chlorambucil, methotrexate, and fluorouracil that may be used in the treatment of breast cancer. 